\title{
SER FEMININA: UMA PERMISSÃO PARA A SOROPOSITIVIDADE?
}

\author{
BEING FEMININE: A PERMISSION FOR BEING SUSCEPTIBLE TO THE HIV/ \\ AIDS VIRUS?
}

Dafne Suit*
Antonio Marcos Chaves $^{* *}$

Suit D, Chaves AM. Ser feminina: uma permissão para a soropositividade? Rev Bras Cresc Desenv Hum 2005; 15(2):82-90.

\begin{abstract}
Resumo: A epidemia HIV/AIDS caracteriza-se hoje, no Brasil, a partir de sua feminização, heterossexualização e pauperização. Análises de contextos sócio-culturais têm indicado que as maneiras como estes estão organizados exercem papel primordial na forma como a infecção é adquirida, entre aquelas pessoas neles inseridas. Em relação à infecção de mulheres, observa-se que o modo como o gênero feminino tem sido construído socialmente torna-se um facilitador para a maior vulnerabilidade das mulheres. Sugerir o uso do preservativo em relacionamentos estáveis ainda é uma prática pouco utilizada e o poder de negociação apresenta-se numa relação inversa ao grau de dependência da mulher. $\mathrm{O}$ ensaio traz uma série de reflexões a respeito da construção social do papel feminino e infecção pelo HIV. Toma como suporte as formulações teóricas propostas pelo modelo do Individualismo e Coletivismo, considerando-se a possibilidade das mulheres, culturalmente, terem um perfil com características mais coletivistas, especialmente, em relação à preservação da comunidade familiar, o que as torna mais vulneráveis à infecção.
\end{abstract}

Palavras-chave: HIV/AIDS. Gênero. Mulher. Individualismo e Coletivismo.

No Brasil, o aumento da infecção por HIV, em mulheres, tem sido motivo para reflexões em torno do que estaria causando a feminização da epidemia de maneira tão rápida. Sabe-se que a proporção homem/mulher deu um salto de 6:1 em 1989, para 2:1 em 1999 e que em 2002 a proporção de 1:1 se tornou uma realidade em algumas capitais de Estado, além da pauperização da epidemia ${ }^{1,2}$. Este quadro não é diferente do que se apresenta em diversas partes do mundo ${ }^{3}$.

Percebe-se que o contexto cultural exerce um papel primordial na forma como a epidemia vem ocorrendo. Variados tipos de pesqui- sa têm se dedicado ao estudo da estruturação deste quadro, sendo já um consenso que a forma como hoje se constrói o gênero feminino é um facilitador para a maior vulnerabilidade das mulheres diante da infecção.

Os conhecimentos básicos a respeito das formas de transmissão do vírus, assim como as maneiras de se prevenir, são conhecidas por grande parte da população feminina ${ }^{4}$. Entretanto, não se notam fortes mudanças no comportamento de autoproteção e os dados estatísticos continuam mostrando que é necessário vincular a epidemia às questões culturais.

A possibilidade de adotar práticas sexu-

\footnotetext{
Programa de Pós-Graduação em Psicologia (UFBA). Rua da Brisa, 42, ap.601 - Pituba, CEP: 41.927-450 Salvador, Bahia

** Programa de Pós-Graduação em Psicologia (UFBA). Endereço para correspondência: Av. Otávio Mangabeira, 11.881, M4-06, CEP: 41.650-000 Salvador (BA). Email: amchaves@ ufba.br
} 
ais mais seguras, que trazem a necessidade do uso de preservativos masculinos, depende da concordância dos homens, sendo que o uso do preservativo não está estabelecido no Brasil, nem como uma prática contraceptiva, já que existe, de um modo geral, a falsa associação do preservativo a um menor prazer sexual ${ }^{5}$.

Sugerir o uso do preservativo, em relacionamentos estáveis, origina uma série de questionamentos, de ambas as partes, a respeito da fidelidade e da confiança ${ }^{6}$. Para os casais pobres e com filhos, onde as mulheres são mais dependentes dos maridos, em termos sociais e financeiros, elas têm menor poder de negociação, estabelecendo-se uma relação inversa entre negociação e grau de dependência ${ }^{7}$.

Assim, neste ensaio, serão abordadas algumas reflexões a respeito da construção social do papel feminino e da maneira como as mulheres vêm se relacionando com o HIV/AIDS, tomando-se como base que o gênero se constrói a partir das práticas culturais e que não se trata de algo meramente biológico. Também serão feitas relações com a Teoria do Individualismo e Coletivismo, considerando-se a possibilidade de que as mulheres estejam dentro de um perfil mais coletivista.

\section{Dados históricos sobre o papel feminino no Brasil}

Durante a colonização, os homens, ao desempenharem o papel de dominadores, tomaram a terra e as mulheres que a habitavam pela força ${ }^{8}$. As mulheres africanas eram vistas no papel de trabalhadoras e de objetos sexuais. As mulheres brancas deviriam preservar o arquétipo de Maria, permanecendo assexuadas e com as vidas restritas aos limites da casa ou da igreja.

Assim, as mulheres brancas sob o estereótipo de fracas, submissas, passivas e sem poder na área pública, não recebiam educação formal e eram treinadas para o casamento. Neste papel elas deveriam administrar a casa, criar os filhos e tolerar as relações extra-matrimoniais do marido com as escravas ${ }^{9}$.

Durante o Império, observaram-se pequenas mudanças, no sentido de ampliar os papéis desempenhados e já era tolerado o trânsito de mulheres nas ruas, havendo uma pequena incursão no mercado de trabalho9.

Somente no fim do século XIX e início do século $\mathrm{XX}$, as mulheres iniciam-se na profissão de professoras, já que esta constituía a profissão mais próxima do papel de mãe exercido até então. A entrada das mulheres no exercício da profissão originou a diminuição dos salários e, mesmo tendo um papel profissional, os papéis de filha, esposa e mãe, continuaram sendo vistos como uma prioridade na vida das mulheres ${ }^{10}$. Além disto, por muitos anos, os direitos trabalhistas das mulheres e crianças foram desconsiderados, em relação aos direitos que os homens possuíam ${ }^{11}$.

A participação das mulheres no mercado de trabalho e sua formação acadêmica tiveram grande crescimento a partir da década de 1970, talvez em decorrência do movimento mundial, iniciado nesta década, do qual o feminismo fazia parte ${ }^{8}$.

Atualmente, percebe-se que as mulheres continuam o seu desenvolvimento profissional. Entretanto, a tendência para relações de maior igualdade entre homens e mulheres, no sentido de que seja abandonada a idéia de que as mulheres devem ser subjugadas pelos homens, é vista, em sua grande maioria, apenas em casais jovens e de classe média ${ }^{12}$. Nas camadas mais empobrecidas, a desigualdade é ainda bastante forte e a sexualidade feminina é construída para ser subordinada às necessidades do marido, sendo o homem considerado como o provedor, que sustenta a família e o seu representante legal.

Além disso, o espaço público continua sendo visto como algo tipicamente masculino e o espaço privado, constituído pelo lar, é algo vinculado ao feminino. No Brasil, não se foge 
ao quadro apresentado em outras culturas, nas quais também se valoriza o espaço público em detrimento do privado ${ }^{13}$.

Para Berer $^{3}$, a vida privada constitui o espaço em que se aprisiona a mulher e, em contrapartida, o homem tem se desenvolvido como protagonista, arriscando-se e aventurando-se. As mulheres têm sido "condenadas" às rotinas familiares, ao cuidado das crianças, preparo da comida e ao servir sexualmente e, mesmo tendo alcançado um status aparentemente igual ao do homem, em termos de educação formal, vida profissional e política, estas conquistas significam o preço da dupla jornada de trabalho.

Observa-se, ainda, que o modelo de Maria é um modelo que se apresenta na constituição do feminino brasileiro de maneira forte. Segundo este modelo, a mulher é idolatrada como uma mártir que se auto-sacrifica e que é submissa aos homens, sendo boa mãe e boa esposa ${ }^{14}$. Trata-se de um processo de "domesticação" da mulher, no qual ela é a responsável pela casa, família, casamento e procriação.

É neste contexto específico que o surgimento do HIV / AIDS necessita ser focalizado. As diversas classes sociais já apresentam uma vulnerabilidade diferenciada para o $\mathrm{HIV}^{27,28}$, sendo as mulheres mais desprovidas de recursos econômicos as mais afetadas pela epidemia. Esta maior vulnerabilidade encontraria sua origem nas relações de gênero predominantes, em que a mulher é vista como submissa ao homem.

\section{Mulheres, sexualidade e HIV / AIDS}

Em oposição à construção da masculinidade, a mulher estrutura a sua sexualidade a partir de um constante desconhecimento do seu corpo, do silêncio diante desta carência de informações e de um conformar-se perante os processos biológicos que vivencia. $\mathrm{O}$ grau de liberdade com que um homem pode expressar sua sexualidade é muito maior do que o grau de liberdade permitido às mulheres, devendo es- tas permanecer reservadas ${ }^{6}$.

Tabus, preconceitos e limites rígidos encontram-se presentes na expressão da sexualidade feminina, dando lugar a estratégias que se destacam pelo uso do silêncio, para poder alcançar as características almejadas de pureza, ingenuidade, fragilidade e inferioridade, necessárias para a constituição e perpetuação da imagem da mulher como moça virgem, esposa fiel e viúva recatada ${ }^{15}$.

O ápice da feminilidade ainda é o direito à maternidade, a partir da união estável com a figura masculina, por meio do casamento. Ser feminina implica em timidez, passividade, fragilidade, dependência e fidelidade que vêm, ao longo dos tempos, permeando as relações de gênero ${ }^{6}$.

Ao serem entrevistadas, mulheres soropositivas apresentaram sinais de submissão no exercício da sua sexualidade, percebendo-se que há carência de comunicação com os parceiros, sendo silenciado qualquer tipo de questionamento, para não provocar desentendimentos na relação, já que o ser mulher presume que é necessário manter-se conformada diante da vida privada do companheiro. Mesmo suspeitando do diagnóstico de soropositividade do parceiro, ou conhecendo sua condição, observou-se que há uma tendência a manter-se na relação, sem conversar sobre o assunto, inviabilizando-se qualquer possibilidade de negociação de práticas sexuais mais seguras para elas $^{5},{ }^{6,16}$.

Em um estudo qualitativo realizado a partir de entrevistas a mulheres com AIDS, os companheiros, em nenhum caso, haviam assumido a responsabilidade pela contaminação delas, assim como não assumiam a bissexualidade ou uso de drogas injetáveis. Ainvisibilidade do mundo masculino para suas parceiras, também nesta pesquisa, apresentou-se de maneira clara ${ }^{5}$.

Tomar providências a este respeito pode significar a necessidade de atuar na construção de uma postura mais ativa diante da vida e de 
uma maior autonomia, tanto econômica como emocional. Apesar das mulheres entrevistadas pressentirem a infidelidade dos maridos, ao saberem de sua soropositividade e terem conhecimento das práticas extraconjugais, vivenciavam sentimentos de dor, que se refletiam na sua auto-estima, revelando uma postura infantilizada, em que predominavam as fantasias e evitavam-se dados de realidade, até não ser mais possível. Reconhecer a realidade traz o emergir de dificuldades pessoais, familiares e econômicas desafiadoras, podendo, inclusive abalar a integridade mental ${ }^{4}$.

O medo do abandono, ao tornar-se menos passiva e menos conformada, pode ser visto como real quando associado à situação econômica, que traz dificuldades concretas, tais como a fome, a doença e o não ter onde morar. Entretanto, o medo imaginário tambémé um fator importante, que pode significar perder uma parte de sua identidade, construída em relação ao parceiro. Segundo Brito e $\mathrm{Cruz}^{17}$, a socialização da mulher é feita para viver em função de e para um homem, que constitui um "pilar" para o existir feminino. A transformação do medo do abandono estabelece a possibilidade de assumir-se como sujeito em seu processo de fortalecimento, diante de si mesma e do outro ${ }^{4}$.

Assumindo sua identidade sexual, decidindo ser ela mesma e vivenciando sua sensualidade e erotismo, a mulher pode tornar-se ameaçadora. Isto não só para os homens, mas também para muitas mulheres que julgam estes comportamentos como pouco femininos, demasiado independentes ou demasiado ambiciosos ${ }^{3}$.

A partir de relatos em oficinas temáticas, Brito e Cruz ${ }^{17}$ observaram que mulheres que eram provedoras em suas famílias e que não tinham marido, sentiam-se menos femininas, dando sustentação à idéia de que um enfrentamento mais ativo da vida é associado à masculinidade, sendo a passividade uma característica que constitui o que se considera como feminino, pelas próprias mulheres.
Nestas oficinas, também se observou o desejo de uma maior igualdade entre os gêneros, mas não uma prática que permitisse isto, já que os homens foram descritos de maneira superior ou inferior, mas nunca igualitária.

A auto-estima destas mulheres mostrouse abalada, podendo expressar uma maior autoaprovação ao perceber-se atendendo aos principais papéis atribuídos ao feminino na nossa cultura, como o de ser uma dona de casa, cuidando do outro e atendendo às suas expectativas.

Em outro estudo realizado, também a partir de entrevistas, mulheres soropositivas revelaram forte preocupação com o cuidado dos filhos e da organização da sua família após a sua morte. O papel de cuidadoras configurou-se a partir da proteção que podiam dar para seus filhos e, muitas vezes, para seus companheiros e demais familiares. Nenhuma das participantes manifestou preocupação com o destino dos filhos a partir da morte do companheiro ${ }^{18}$.

Estes dados coincidem com dados obtidos no México ${ }^{3}$, em que as mulheres se sentiam incapazes de abandonar seus filhos ou companheiros com HIV/AIDS, cuidando deles, mesmo que isto pudesse significar deixar a sua saúde em segundo plano.

A dificuldade de buscar o cuidado para si próprias, por estar cuidando do parceiro e, por vezes, também de filhos soropositivos, também foi abordada por Vermelho, Barbosa e Nogueira $^{5}$, no Brasil. Assim, o diagnóstico e o tratamento tardio de mulheres soropositivas constituem um outro ponto de vulnerabilidade social, que encurta o tempo e qualidade de vida das mulheres portadoras do HIV em relação aos homens. A descoberta da soropositividade ocorre, na maioria dos casos, a partir do adoecimento ou morte do marido, dos filhos ou do seu próprio adoecimento, percebendo-se que os cuidados com a saúde não são uma rotina para esta população, tratando-se muito mais de uma questão de ocasião ou oportunidade.

Para os homens, conhecer a soropositi- 
vidade das esposas origina o abandono das famílias, em maior freqüência ${ }^{3,16}$. Poder ser cuidada e apoiada parece ser uma realidade distante das mulheres soropositivas, dentro da relação com seus companheiros, e a sua assistência pós diagnóstica, ocorre a partir de outras mulheres, tais como, mães, irmãs, tias ou mesmo vizinhas, quando ocorre, já que o sentimento de solidão e abandono é alto nos seus depoimentos ${ }^{5}$.

O papel de cuidadora é dado às mulheres, ao mesmo tempo em que este não é visto como algo tão valorizado quanto os papéis que são dados aos homens. Assim, as próprias mulheres não valorizando aquilo que fazem, sentindo-se culpadas ao se perceberem não gostando do desempenho deste papel ${ }^{3}$.

A partir destes dados, ser mulher pode associar-se a uma maneira mais coletivista de lidar com a vida e menos individualista, em contrapartida ao masculino, que pode se relacionar a um maior individualismo e a um menor coletivismo. Abordar o estudo das relações de gênero por esta perspectiva teórica torna-se importante para auxiliar na compreensão dos processos de desenvolvimento do ser feminino.

\section{A Teoria do Individualismo e Coletivismo}

As raízes do individualismo encontramse na Revolução Francesa, sendo associado à defesa dos direitos individuais e pressupondose que este constituiria uma ameaça ao bemestar da comunidade ${ }^{18}$. Entretanto, o individualismo e o coletivismo passaram a ser tema de pesquisa somente a partir da década de $1980^{19}$, sendo o trabalho de pesquisa de Hofstede ${ }^{20}$, considerado como um marco neste campo.

Em seu trabalho, Hofstede ${ }^{20}$, a partir daavaliação de trabalhadores da empresa IBM, realizou um estudo comparativo em aproximaamente 50 países, numa tentativa de encontrar dimensões básicas da variação cultural, como o individualismo-coletivismo, criando assimuma tipologia que permitiria perceber um ambiente cultural como mais individualista ou mais coletivista $^{21}$.

A literatura parece unânime ao considerar que o coletivismo seria uma maneira natural de existir, que caracterizaria culturas em graus menores de desenvolvimento, assim como o individualismo estaria associado a uma construção a partir da complexidade que o meio social vai adquirindo. As sociedades ocidentais, industrializadas teriam um perfil mais individualista, ao mesmo tempo em que as demais sociedades, mais voltadas para a tradição, estariam dentro do perfil delineado para o coletivismo.

\section{O Individualismo}

Caracterizado pelo respeito às necessidades individuais, à privacidade, havendo uma ênfase na obtenção de satisfações pessoais e que são atingidas a partir de esforços autônomos. Nas relações interpessoais, haveria a valorização dos direitos de cada um, em detrimento dos deveres que cada pessoa teria para com seu semelhante. O status e os papéis são definidos em função dos êxitos que o indivíduo possa atingir, tais como, o educacional, o ocupacional e o econômico ${ }^{21}$.

A associação das pessoas ocorreria, nestas culturas, a partir de interesses semelhantes, sendo a participação grupal avaliada constantemente, numa tentativa de verificação do ganho que se está obtendo a partir das associações. Continuar participando de associações em que se está obtendo um maior custo, não faz parte da cultura individualista ${ }^{18}$.

Assim, a ruptura com os ancestrais e a separação dos familiares estariam calcadas em relações "contratuais", ocorrendo no momento em que estas relações passam a constituir uma ameaça ao desenvolvimento dos interesses individuais. $\mathrm{O}$ contexto social em que a pessoa se encontra estaria em um nível secundário de importância ${ }^{22}$, valorizando-se a liberdade de 
escolha, o controle pessoal.

O individualismo, para Triandis ${ }^{23}$, pode ser diferenciado a partir de dois atributos principais: horizontal e vertical. O individualismo horizontal seria caracterizado pela alta liberdade das pessoas e igualdade entre elas, o eu seria independente, mas não diferente dos demais membros de seu contexto. Pessoas assim orientadas teriam a necessidade de distinguirse dos grupos, desenvolvendo autoconfiança e a sensação de serem pessoas "únicas". Pessoas orientadas pelo individualismo vertical valorizariam o eu independente, diferente dos demais, entretanto, aceitando a baixa igualdade entre os membros de seu contexto, buscando o êxito e o destacar-se dos outros, sendo o "melhor" e tendo maior prestígio.

\section{O Coletivismo}

Caracterizado pela importância dada à obtenção do bem comum e da harmonia social, que prevaleceria diante dos interesses individuais. Uma rede de inter-relações tornaria as pessoas encaixadas e situadas em papéis que facilitariam a construção de um destino comum, sendo os interesses grupais primordiais.

Nesta perspectiva, os deveres e obrigações são descritos a partir da definição dos papéis que cada um detém no contexto grupal, perdendo-se o prestígio ao falhar no seu cumprimento. A ordem social é mantida a partir do cumprimento de papéis e deveres, sendo desencorajada a expressão de desejos individualistas e hedonistas ${ }^{21}$.

Os grupos são vistos como unidades de sobrevivência sendo as pessoas parte inseparável deles. Uma forte tendência à cooperação e ao cumprimento dos deveres para com os semelhantes estaria presente no coletivismo.

Triandis ${ }^{23}$ destaca que também o coletivismo pode ser diferenciado nos atributos de horizontalidade e verticalidade. O coletivismo horizontal se caracterizaria pela baixa liberda- de, mas por uma alta igualdade, percebendose as pessoas como similares às outras, enfatizando os objetivos comuns, buscando a interdependência e a sociedade, sem submeter-se de modo fácil à autoridade. Ser cooperativo é básico nesta orientação. No coletivismo vertical, haveria um baixo sentido de liberdade e igualdade e as pessoas seriam caracterizadas por serem servidoras, fazendo sacrifícios em benefício de seu grupo e cumprindo as obrigações impostas por normas sociais. O eu mostra-se, nesta orientação, como interdependente, porém, diferente dos demais.

\section{O desenvolvimento da teoria}

Tratando-se de uma teoria iniciada apenas há duas décadas, encontra-se em fase de estruturação, com muitos estudos empíricos que tanto a contradizem quanto a completam em andamento. Atualmente, o individualismo e o coletivismo são concebidos como duas orientações que podem coexistir tanto numa mesma pessoa, como numa mesma cultura ${ }^{23,24,29}$.

Assim, perceber de que forma o gênero feminino se situa a partir desta teoria parece possível, podendo atuar como fonte para esclarecimentos sobre as motivações que estariam presentes no dia a dia das mulheres ao relacionar-se em seus contextos familiares e nas associações que constróem com os homens.

\section{Mulheres e coletivismo}

A partir das informações analisadas, observa-se que a formação do gênero feminino pode relacionar-se a um maior índice de coletivismo, ao analisar as relações que as mulheres estabelecem com seus companheiros e famílias.

O ideal de submissão e dependência, assim como o auto-sacrifício que as mulheres mostram diante da figura masculina, pode ser identificado como o coletivismo vertical descrito por Triandis ${ }^{23}$. 
Conformar-se diante dos papéis que a legitimam como mulher seria uma forma de obedecer às normas sociais que são estabelecidas pelo grupo e os processos biológicos que diferenciam a sexualidade feminina identificam-se como fonte para uma maior passividade, deixando de lado ideais de autonomia e independência.

Para que uma mulher seja vista em sua plenitude parece necessário que ela esteja no exercício do papel de cuidadora, de mãe e dentro da legalidade de uma relação estável. Isto precisa ser mantido, sob pena de perder sua identidade, que se encontra na coletividade da família. A auto-estima estaria diretamente associada ao bom desempenho nos papéis que lhe são delimitados.

Não é estranho que fazer parte do grupo familiar e deixar de lado a sua individualidade, em favor dos interesses grupais, tem se apresentado de maneira freqüente na literatura a respeito de mulheres e HIV/AIDS. Assim, o cuidado do outro, seja marido, filhos e demais membros familiares, pareceu ser mais importante, para estas mulheres, do que o cuidado consigo.

Foram enfatizadas também as dependências econômica e emocional, que, para Kagitçibasi ${ }^{25}$ originariam um modelo de coletivismo, sendo a plena independência material e emocional característica do individualismo.

Em uma revisão de literatura realizada por Oyserman e $\mathrm{Swin}^{26}$ a respeito de estigma, salienta-se que pessoas que possuem menor poder estariam mais atentas àquilo que é dito pelo ambiente externo, em diversas linguagens. Enquanto que aquelas que detêm o poder, focalizam-se no individualismo e não nas limitações que o contexto apresenta. Além disso, as mulheres são consideradas como mais relacionais na definição de seus auto-conceitos, mostran- do-se mais sensíveis ao feedback que o contexto lhes apresenta, adotando posturas mais adaptativas àquilo que se espera delas.

O silêncio, descrito como maneira de evitar conflitos na relação, estaria diretamente relacionado ao interesse coletivista de manter a harmonia familiar, buscando a coesão do grupo e descartando as motivações individuais. Assim, o auto-sacrifício, presente no deixar de lado a infidelidade masculina, pode ser relacionado ao dar maior importância à manutenção do núcleo familiar.

Estes dados constituem reflexões que poderiam ser respaldadas por mais investigações a este respeito, já que ainda se trata de um campo de pesquisas bastante novo, dentro da perspectiva da psicologia transcultural.

\section{CONSIDERAÇÕES FINAIS}

A Teoria do Coletivismo-Individualismo tem sofrido diversas críticas por parte dos psicólogos que adotam a abordagem culturalista que nega poder se comparar culturas, já que esta teoria seria uma tentativa de encontrar pontos em comum entre as diversas culturas, além de considerar que o coletivismo seria uma maneira menos desenvolvida de se relacionar, valorizando-se o individualismo.

A cultura, neste caso, é considerada como uma variável independente, que estaria originando o comportamento individualista ou coletivista.

Entretanto, trata-se de um campo de pesquisas em crescimento em que as propostas transculturais e culturais podem vir a se complementar, assim como também deve ser considerada a perspectiva da masculinidade em tal complementação.

\footnotetext{
Abstract: From a socio-cultural perspective, the HIV/AIDS epidemic course is nowadays characterized in Brazil as a broader context in which the social dimension is organized and inextricably links feminization, heterosexuality and poverty. Systematic analysis of socio-cultural
} 
contexts has been indicating that the pattern in which these elements are organized has an important role in the path infection has acquired among those people inserted in those contexts. Regarding women's infection, it has been observed that the female gender in Brazil finds itself vulnerable to a rising mortality rate. The findings show that the social pattern in which the feminine gender has been socially built turned to be a facilitator for women's vulnerability. Suggesting the use of prophylactics in stable relationships is an uncommon practice and women's power of negotiation for such seems to be inversely proportional to women's dependence on the male who is the head of the family. This text brings a series of reflections concerning the social construction of the feminine role and infection by HIV. Taking into consideration, as a theoretical standpoint, the Individualism/Collectivism model, it considers the possibility that women have a cultural profile that enables them to be more centered on the collective dimension, especially regarding the preservation of family community, which makes them be more vulnerable to the infection.

Key words: HIV/AIDS. Gender. Woman. Individualism and Collectivism.

\section{REFERÊNCIAS}

1. Brasil. Ministério da Saúde. Boletim epidemiológico AIDS 1998; 12(1).

2. Brasil. Ministério da Saúde. Boletim epidemiológico AIDS 2002;15(2).

3. Berer M. La mujer y el VIH/SIDA. London: Bath Press; 1993.

4. Alves RN, Kovács MJ, Stall RPV. Fatores psicossociais e a infecção por HIV em mulheres. Revista de Saúde Pública 2002; 36(4): 32-9.

5. Vermelho LL, Barbosa RHS, Nogueira SA. Mulheres com AIDS: desvendando histórias de risco. Cadernos de Saúde Pública 1999; 15(2): 369-79.

6. Guimarães K. Nas raízes do silêncio: a representação cultural da sexualidade feminina e a prevenção do HIV/AIDS. In: Parker R, Galvão J, editores. Quebrando o silêncio: mulheres e AIDS no Brasil. Rio de Janeiro: Reluma Dumurá/ABIA/IMSUERJ; 1996.

7. O'Leary S, Cheney B. A tripla ameaça - mulheres eAIDS: Dossiê Panos. Rio de Janeiro: ABIA; 1993.

8. Souza E, Baldwin JR, Rosa FH. A construção social dos papéis sexuais femininos. Psicologia Reflexão e Crítica 2000; 13(3): 485-96.

9. Costa EV da. The Brazilian empire: myths and histories. Chicago: University of Chicago Press; 1985.

10. Hahner JE. Emancipating the female sex: the struggle for women's rights in Brazil, 1850-1940. Durhan: Duke University Press; 1990.

11. Burns M. A history of Brazil. New York: Columbia University Press; 1993.

12. Miller $\mathrm{C}$. The function of middle-class extended family networks in Brazilian urban society. In:
Margolis M, Carter W, editores. Brazil: anthropological perspectives. New York: Columbia University Press; 1979.

13. Arrazola ID, Rocha I. Mulher, natureza, cultura: apontamentos para um debate. In: Rabay G, editor. Mulheres e sociedade. João Pessoa: UFPB/ Editora Universitária; 1996, p. 45-55.

14. Neuhouser K. Sources of women's power and status among the urban poor in contemporary Brazil. Signs 1989; 14: 685-702.

15. Heilborn ML, editor. Vivência. História, sexualidade e imagens femininas. São Paulo: Brasiliense/Fundação Carlos Chagas/Fundação Ford, 1980.

16. Bruyn M. Women and AIDS in developing countries. Soc. Sci. Med 1992; 34(3): 249-62.

17. Brito N, Cruz EF. Fios da vida: tecendo o feminino em tempos de AIDS. Brasília: Ministério da Saúde; 2000.

18. Oyserman D, Coon HM, Kemmelmeier M. Rethinking individualism and collectivism: evaluation of theoretical assumptions and metaanalyses. Psychological Bulletin 2002; 128(1): 372.

19. Kagitçibasi Ç, Berry JW. Cross cultural psychology: current research and trends. Annual Review of Psychology 1989; 40: 493-531.

20. Hofstede G. Cultures's consequences: international differences in work-related values. Beverly Hills: Sage; 1984.

21. Gouveia VV, Clemente M. O individualismocoletivismo no Brasil e na Espanha. Estudos de Psicologia 2000; 5(2): 317-346.

22. Gouveia VV, Andrade JM, Jesus GR, Meira M, Soares NF. Escala multi-fatorial de individualismo e coletivismo: elaboração e validação do 
construto. Psicologia: Teoria e Pesquisa 2002; 18(2): 203-12.

23. Triandis HC. Individualism and collectivism. Boulder: Westview; 1995.

24. Schwartz SH. Individualism-collectivism: Critique and proposed refinements. Journal of CrossCultural Psychology 1990; 21:139-57.

25. Kagistçibasi Ç. A critical appraisal of individualism and collectivism: toward a new formulation. In: Kim U, Triandis HC, Kagitçibasi Ç, Choi SC, Yong G, editores. Individualism and collectivism: theory, method and applications. Thousand Oaks: Sage; 1994. p. 52-65.
26. Oyserman D, Swim JK. Stigma: an insider's view. Journal of Social Issues 2001; 57(1): 1-14.

27. Bastos FI, Szwarcwald CL. AIDS e pauperização: principais conceitos e evidências empíricas. Cadernos de Saúde Pública 2000; 16 Supl.1:65-76.

28. Parker R, Camargo Jr KR. Pobreza e HIV/AIDS: aspectos antropológicos e sociológicos. Cadernos de Saúde Pública 2000; 16 Supl: 89-102.

29. Ferreira MC, Assmar EML, Souto S de O. O individualismo e o coletivismo como indicadores de culturas nacionais: convergências e divergências teórico-metodológicas. Psicologia em Estudo 2002; 7(1):81-9.

Recebido em 15/04/2005

Modificado em 06/06/2005

Aprovado em 13/06/2005 